\title{
GLOBAL CITIZENSHIP AMID TRANSITIONAL PERIODS AND INCREASED IMPORTANCE OF STEM AND SCIENCE DIPLOMACY
}

\author{
Eric Jason Simeon
}

Adjunct Prof. PhD./Researcher, The Harbor Institute, The United States, ejsimeon92@yahoo.com

\begin{abstract}
The author reflected on government funded cross-national/multi-institutional comparative research, which focused on issues of citizenship in global contexts, the multiple uses of STEM, and individual and group rights via geopolitical alliances. The promotion of diversity and citizenship competencies demonstrates an international commitment to strengthen the bonds between nations through the education of citizens in critical fields (e.g. STEM) and further integration into the global system of scientific innovation that connects global partners and promotes what is best for societal peace and prosperity. National and global citizenship are examined in these contexts.

In this manuscript I will: 1) discuss contemporary debates for and against global citizenship that are driving many of today's national policies around the globe (i.e. US immigration policy, Brexit); 2) explicate the expansion of ideas regarding national issues in a global context and rising belief in international collaboration to deal with those issues (global citizenship); 3) elucidate our methodological approaches; 4) examine how the STEM pipeline is affected by anti-global citizenship policies; and 5) synthesize the ways that STEM promotes collaboration in dealing with global issues (i.e. Science Diplomacy, COVID-19 response).

Educating economically successful engaged global citizens; expanding access to higher education; and impacting science diplomacy, international relations, and the evolution of the academy into engines of social and economic development are all issues that have been addressed through the promotion and expansion of international STEM collaborations. The conceptual literature review and analysis elucidates perspectives that show that engagements bring gifted scientists and students together from across the globe to work on issues of international significance. Hence the essence of cosmopolitanism, global citizenship education, and the global university engagement movement are portrayed.

By linking global citizenship education with that of STEM education in comprehensive holistic manners, the preparation of students will promote the understanding of informed global perspectives uninhibited by border that include various populaces and viewpoints. The ideas/policies of promoting informed global perspectives through civic engagement and citizenship are an embrace of sociocultural and globally inclusive paradigms that portray beneficial results. By working collectively with various current and future higher education, government, and STEM professionals physical and cultural barriers can also be dismantled.
\end{abstract}

Keywords: Global Citizenship, STEM, Diversity.

\section{INTRODUCTION}

In 2018 and 2019, the author engaged in interactions with professionals working with US federally funded non-government organizations (NGOs) that were involved with "undocumented" migrants that have been accused of causing a national crisis by attempting to enter the Southern border of the United States (U.S.). A 
number of these professionals were themselves migrants from West African and South American countries. These colleagues shared that they came from countries engaged in civil conflict, strife, terrorism, \& conflict between indigenous citizens and the ruling class. In short, these professionals had fled their home countries due to the absence of social justice and economic opportunities. Yet, they were now in positions to implement official American policies against individuals, who were seeking similar viable options via migration.

These realities prompted the author to reflect on government funded cross-national research in the U.S. and England where migrants immigrated particularly since the 1940s in search of opportunities in the aftermath of formal colonialism. Such migrants and/or their descendants are often engaged in STEM fields or poised to become STEM professionals after completing graduate degrees. Fundamental issues of citizenship in global contexts, the multiple uses of STEM, and individual and group rights via geopolitical alliances come to the forefront.

Matters regarding how to address critical domestic and international issues will be based, in considerable part, upon professionals who are technically skilled in STEM. Subsequently, the development and application of STEM policies in relation to sociopolitical and cultural problems should enhance the lives of individuals regardless of ethnic or national origins. The promotion of diversity and citizenship competencies also demonstrates an international commitment to strengthen the bonds between nations through the education of citizens in critical fields (e.g. STEM) and further integration into the global system of scientific innovation that connects global partners (American University in Cairo and the University of California Davis) [UC Davis, 2019; Office of White House, 2015] and promotes what is best for societal peace and prosperity. National and global citizenship are examined in these contexts.

Thus, in this manuscript I will: 1) discuss the contemporary debate for and against global citizenship that are driving many of today's national policies around the globe (i.e. U.S. immigration policy, Brexit); 2) explicate the expansion of ideas regarding national issues in a global context and rising belief in international collaboration to deal with those issues (global citizenship); 3) elucidate the methodological approaches; 4) examine how the STEM pipeline is affected by anti-global citizenship policies; and 5) synthesize the ways that STEM promotes collaboration in dealing with global issues (i.e. Science Diplomacy, pandemic response [COVID-19]). Items one and two will encompass the literature review and content analysis in structuring this paper, and will encompass the contextual and conceptual frameworks. The paper will conclude with statements by national leaders, influential domestic and international policymakers, who voice the necessity of cooperative STEM, citizenship, and global enterprises.

\section{THE GLOBAL CITIZENSHIP DEBATE}

The introduction of the concept of global citizenship dates back to the 4th century B.C. when the Greek philosopher Diogenes declared that he was a "citizen of the world" and that people would see themselves more clearly "when [they see their] ways in relation to those of others." (Trotta-Tuomi, Jacott, \& Lundgren, 2008 , p. 2). Since that time global citizenship has evolved side-by-side with globalization and has become the basis of our global society, as countries and universities have continued to build closer international connections through economic, military, and related alliances (The Balance, 2019). This was highlighted throughout the administration of President Barak Obama, who stated that, "Learning to stand in somebody else's shoes, to see through their eyes, that's how peace begins... understanding the complexity of our world, appreciating the diversity of cultures that exists across continents. And in the end...using all that knowledge to help bridge divides and bring people together" (Washington Post, 2009; Tau, 2012). The high levels of internationalization among STEM education programs, and the ways they are evolving, allow them to continuously promote global citizenship competencies, because they deal with issues that are global in scope (disease research; nuclear proliferation; environmental sustainability; etc.), and have become natural laboratories for the promotion of the understanding of core global citizenship values (Starkey, 2017; Simeon \& Lindsay, 2015; Lindsay \& Simeon, 2015; Knight, 2008).

Despite the spread of global connectedness and global citizenship competencies across aspects of society (Institute of International Education [IIE], 2018) there has been an increasing international pushback against these beliefs. This can be seen in the economic, immigration/refugee, foreign aid, and human rights policies of the Trump administration in the U.S. (McCarthy, 2017); the surprising outcome of the Brexit vote in the United Kingdom (UK) in 2016 (Tharoor, 2016); and the legitimizing and tightening of totalitarian regimes around the world (ex. Russia, Turkey, Syria) [Bolton, 2018]. In 2016, after the Brexit vote was final, Theresa May stated, "...if you believe you are a citizen of the world, you are a citizen of nowhere...[and] don't understand what citizenship means" (Bearak, 2016). She not only highlighted Britain's increasingly nationalist leanings (Tharoor, 2016), but also laid out the stance that her conservative party would take when it came to negotiating the UKs departure from the European Union (EU). 
Similar nationalist shifts have been observed across the industrialized world including throughout the European Union, in places like Switzerland, Sweden, and Finland, some of the world's most liberal democratic nations, where nationalist leaning parties hold almost $20 \%$ of the seats in their parliament (BBC News, 2018). In Germany, nationalism is increasing as evinced with approximately $12.6 \%$ of the Bundestag espouse nationalism (a first since the end of World War II) [BBC News, 2018]. Even in the U.S., under the current Presidential administration, there has been a revitalization in nationalist rhetoric brought on by the strong anti-religious views of some faiths and statements such as, "A new vision will govern our land. From this day forward it's going to be only America first, America first" (McCarthy, 2017). This type of rhetoric has also been labeled as destructive to international alliances, security, and safety (Bolton, 2018).

\section{METHODOLOGY}

This section uses the method of content analysis to identify patterns in recorded communication. The information is based upon research protocols from two National Science Foundation (NSF) grants; the NSF is a US government funded agency that supports fundamental research and education in non-medical fields of science and engineering (National Science Foundation, 2020). The grants examined diversification of STEM graduate programs in the U.S. and England. Within the U.S. the research encompassed interviews with students and senior professionals from American urban Tier I or II Research universities (those that offer a comprehensive range of doctoral programs), as well as Russell Group universities in England (the top 25 plus research universities). All the participants are citizens or permanent residents of their respective nations and attended or worked at public urban universities. Semi-structured, interviews offered considerable insight, from multiple perspectives, into the development of global citizenship competencies through STEM program exchanges. Due to confidentiality requirements both the research sites and the participants remain anonymous.

Approximately 150 interviews were conducted. The sample was evenly divided based on gender, but consisted mostly of underrepresented racial/ethnic minority students, along with faculty and administrators, in order to focus on ideas of diversity and inclusion. All of the interviewees voiced the importance of their STEM expertise and related STEM to cultural realities and globalization via cooperative research within and among nations. Interestingly, while STEM is critical in all nations, how it benefits various populaces is determined, in part, by cultural norms manifested by policies of domestic and international organizations.

\section{THE EXPANSION OF IDEAS OF NATIONAL ISSUES IN A GLOBAL CONTEXT}

The ideas of global citizenship cannot be discussed without first talking about the historical influences of colonialism, capitalism, and globalization, and how they have evolved together to form today's definition of cosmopolitanism, which is a hybridized form of modern global citizenship. The results are an instilled sense of moral responsibility for global issues while providing the capital to be competitive in the global market (Lindsay \& Simeon, 2014; Rhodes \& Szelenyi, 2011). The ideas are underlined by tenets of cosmopolitanism that seek to mold individuals that can partake in meaningful engagement with different cultures and can balance their identity between the local and global contexts (Aoun, 2019; The Global Educator, 2013). The balance of identities that make up cosmopolitanism in the $21^{\text {st }}$ century (repackaged as global citizenship), also instills ethical feeling of responsibility and social justice alongside an economically-aware global competence (The Global Educator, 2013).

The saliences of identity by dominant group(s), which initially seems to be based on appearance, provide today's overarching sociopolitical and economic realities. With the statuses of intra-domestic and international migration, as well as intimate relations among groups of people, appearances can be more difficult in defining individuals and groups and their subsequent treatment. Smith (2014) found that organizations need to undergo transformative changes to meet evolving and historical identities that emerged due to the movements of people, and development of new types of relationships among groups.

Education at all levels is a basis for shaping cosmopolitan identities and attitudes towards citizenship, and thus may lead in the development of epistemic virtues, critical thinking/learning skills, and an appreciation for the cultural commonalities that stimulate 'global thinking'. This will allow for the questioning of contemporary practices and global structures in a way that allows for the development of global solidarity (Rizvi, 2009). Cosmopolitan competencies (which are naturally multicultural) seek to bring society and cultures together in the "community of dialogue...[based-on]...interlocking commonality..." (Nussbaum, 1996, pg. 3). This allows them to define themselves through their local identity (nationalism) while also understanding and accepting humanity in all forms, and recognizing, despite differences, commonalities in aims, aspiration, cultures, histories, traditions, and values (Nussbaum, 1996). A person with a global perspective will develop increased levels of cultural awareness, enhanced ability to compromise (Hayden, Rancic \& Thompson 2000), and will allow them to see how their actions impact their communities, both local and global (Marshall, 2007). 
On the macro-level, the ideal cosmopolitan situations result in a more participatory culture that have lowered barriers to civic engagement, strong support/sharing mechanisms, mentorship, and a belief that contributions matter. This promotes social connections based-on positive community (local and global) contributions that signal engagement and identity through norms and practices. Global civic engagement like this requires an understanding of community membership and behaviors based-on an awareness of others, and which allows for replication that will then result in community membership and development (Haythornthwaite, 2009). Social reconstruction along these lines, via civic engagement, is a multi-layered and hybridized form of citizenship education (Delacruz, 2009) that challenges us versus them thinking.

Higher Education Institutions (HEls) play a key role in the perpetuation of identity, nationalism, and citizenship, while focusing-on the hybrid-nature of contemporary life as a key process contributing to global engagement. The developments of these competencies are necessary in today's constantly evolving world, which is framed by global perspectives that play a central role in providing a safe space for the building of ideas of expanded citizenship and civic engagement (Choudaha \& Contreras, 2014; Watson, 2011; Giroux, 2004). HEls exert influence over the development of global citizenship competencies and play unique roles in how a nation defines citizenship through contributions that aim to better society through their roles as social change agents. This reinforces models of global citizenship grounded in the university experience and become critical to advancing cosmopolitan ideals of the citizen (Rhodes \& Szelenyi, 2011).

The concepts of global citizenship detailed above have found a natural breeding ground and policy laboratory through the continued internationalization of STEM at today's globally-centered universities. This can be seen in the proliferation of international science collaborations and exchanges (Campbell, 2012; Thorson, 2012), federal grant initiatives (the NSF's AGEP program), as well as federal policy initiative (International Visitors Leadership Program, and H.R. 4483) that are aimed at promoting the development of STEM professionals, especially those from underrepresented populations (Simeon, 2016).

When viewing possible policy implications for the development of global citizenship, the concept of science diplomacy has been gaining traction as one of the most important bargaining chips in international affairs. This perspective has gained popularity with international affairs practitioner because it uses the global reach that is inherent in STEM to promote multi-lateral science collaborations with the intent of attaining better international relations and global harmony (CRDF Global, 2014). The use of science as a diplomatic tool provides a policy framework for global citizenship, as future diplomats must develop a professional skillset that includes an understanding of STEM, and its effects on matters of global scope. By turning global science concerns into paths for peaceful relations, science diplomacy embodies the ideals and values of global citizenship. Science diplomacy embraces Nussbaum's (1996) idea of living in dual communities (local/ global), and is an example of global citizenship and STEM operating in policy form, and demonstrates how international STEM collaborations lead to continuous sharing of innovation, technology, and culture/ identity.

Science diplomacy is used as an umbrella term to describe formal or informal technical, research-based, and academic exchanges (American Association for the Advancement of Science [AAAS], 2019; The Royal Society, 2010; U.S. Embassy London, 2014). Such diplomacy components are drawn from the perspective that scientific values of rationality and transparency are universal, underpin good governance, builds trust between nations, and provides an environment for the free exchange of ideas (Royal Society, 2010). Science diplomacy is driven by the need to access the best researchers, facilities, and funding sources (Royal Society, 2010) to invest in the overall global good and addressing global challenges through economic strength and investment (Nye, 2007). When formal diplomatic relations are absent science diplomacy provides the necessary bridge for engagement between nations to build capacity and develop systems and infrastructures that promote open and stable governments that seek to alleviate poverty through economic growth that mitigates the influence of dictators and terrorists (Campbell, 2012; Thorson, 2012). The connections between science and diplomacy has gained traction at the highest political levels as a valuable strategic approach to international collaborations that address common problems, build constructive partnerships, and may foster a diverse community of stakeholders (AAAS, 2014; CRDF Global, 2014). Science and diplomacy practitioners are driving the intellectual development and operation of science diplomacy with the hopes of advancing security and global prosperity; opening access to information; establishing critical partnerships; building global capacity; promoting scientific collaboration; addressing global challenges; and promoting social justice (CRDF Global, 2014; Royal Society, 2010; AAAS, 2014).

\section{EFFECTS OF ANTI-GLOBAL CITIZENSHIP POLICIES ON THE STEM PIPELINE}

As outlined above the nature of global citizenship and the scientific method share similar core values and beliefs, and thus mesh well in the educational context to provide a mutually beneficial, almost symbiotic, relationship between HEls and professional disciplines across all fields, as well as the military. In this relationship universities and colleges provide professionals for industry and the military, which keeps U.S. 
innovation and security at or near the top in the world. In return both industry and the military invest in universities through the funding of research, programs, scholarships, faculty endowments, exchanges/partnerships, and facilities and equipment. Along with promoting the growth of global citizenship development, STEM disciplines also serve as ideal incubator for the promotion of the physical diversification of the academic landscape, both in the form of student and faculty populations.

Research by the author in the U.S. and England, as well in other nations, has portrayed that the fostering of underrepresented students in STEM from diverse racial and ethnic backgrounds as an optimum option for both countries to remain at the forefront of global economic and scientific innovation. Put simply, in order to maintain its global edge, the U.S. should continue to fund initiatives that promote global citizenship development through STEM. However, this is in direct conflict with the course of action laid out by the current presidential administration and their views on migration, immigration, education, and social justice (McCarthy, 2017; McCarthy, 2018). The "America First" views of the current administration around these issues could have detrimental impacts on the reciprocal relationship between academia and industry mentioned above, and eventually the country's standing in the world.

The administration's overall policies on immigration, especially from South/Central America and Mexico, have focused on sweeping changes that include cuts to legal immigration, a wall across the southern U.S. border with Mexico, and extremely strict vetting of all applicants. These policies have manifested themselves in multiple forms including expanded priorities for immigration enforcement that has resulted in increased arrests and removals of unauthorized immigrants (seemingly focused on those from "developing" countries over those from more "developed" countries), as well as the banning of nationals from eight (Muslim majority) countries from entering the U.S.. Attempts to cancel the Deferred Action for Childhood Arrivals (DACA) program, which places numerous undocumented college students, a.k.a. D.R.E.A.M.E.R.S. (many of whom are in STEM majors and who grew up in the U.S.) at risk of being deported (Pierce \& Selee, 2017; Pierce, Bolter, \& Selee, 2018; Nowrasteh, 2018). The ending of Temporary Protection Status (TPS) for nationals of several countries focused largely on those from developing and Muslim majority countries - thus putting several STEM professionals in danger of deportation (Pierce \& Selee, 2017; Pierce, Bolter, \& Selee, 2018; Nowrasteh, 2018). Additional subtle adjustments include extensive mandated interviews for all visa applicants (effecting potential STEM students hoping to study, work, and immigrate to the U.S.); the possibility of family separations; and increased security around visa applicants (especially those with access to technology, i.e. STEM students) (Pierce \& Selee, 2017; Pierce, Bolter, \& Selee, 2018; Nowrasteh, 2018; Semotiuk, 2018).

An example of one of the most immediate impacts of these policies have been in the significant decline $(17 \%)$ in the number of international students applying for $\mathrm{H}-1 \mathrm{~B}$ student visas, of which over 200,000 had applied under the Optional Practical Training (OPT) program that gives special allowances to those in STEM majors (Blumenthal, 2019; Nowrasteh, 2018; Merrick, 2018; Turak, 2018; Semotiuk, 2018). OPT allows STEM graduates to work in the country for up to three years post-graduation, which is a major draw for international students, making U.S. universities desired destinations, with many choosing to become permanent resident and citizens. Fear in cutbacks or the outright cancellation of this program has directly impacted the decline in these numbers (Nowrasteh, 2018; Merrick, 2018; Semotiuk, 2018). This has impacted American universities and colleges around the country, where many, including Yale, Princeton, and Brown have reclassified many majors as STEM programs, while other HEls have re-designated many of their programs as STEM programs (Merrick, 2018; Turak, 2018; Semotiuk, 2018). With 80\% of STEM graduate students at U.S. universities enrolled in electrical engineering and computer science majors having international status many HEls and policy groups have warned that the continued loss of international STEM students due to the shrinking F-1 program could "cause science and engineering programs to shrink or disappear". This would leave the U.S. less prepared to compete globally and would hinder the development of its workforce, and would give a boost to economic competitors like Russia and China (Merrick, 2018; Hatmaker, 2018; Turak, 2018; Semotiuk, 2018).

The combination of these policy adjustments, which have broken the longstanding bipartisan consensus that immigration is a positive for society and the economy has been replaced by a belief that it is a threat to both, have moved the U.S. towards the administration's ultimate goal of decreasing immigrant admissions and increasing deportations. Resistance from opposition groups and pending court cases/rulings that have kept many of these policies from being enforced and exerting immediate impacts (Pierce \& Selee, 2017; Pierce, Bolter, \& Selee, 2018). Hence many experts feel that the unforeseen consequences of these policy shifts (specifically cuts to legal immigration, extreme vetting of applicants, banning of foreign nationals, attempts to cancel the DACA program, cancelling of TPS status), could have a detrimental effect on the number of future professionals entering the STEM pipeline, international alliances built on STEM exchanges, and also the quality of life for those that receive aid (McCarthy, 2017; McCarthy, 2018; Nowrasteh, 2018). 
These fears could become a hard reality in Britain now that the initial phase of Brexit has been finalized (The Week- Business, 2019; BBC News, 2019). Since the 2016 referendum was passed there were fears that the economy would slow, as would job growth and recruitment, especially in fields directly related to STEM. In turn, innovation and overall economic growth will be affected (Clifton, 2019; Prospect, 2019b; Mabbett, 2018; CIPD, 2018; Partington, 2018). Prospect is the UK's largest union that represents professional engineers and other STEM professionals with over 144,000 members across multiple diverse fields including agriculture, broadcasting, defense, education, social services, energy/environment, telecom, and shipbuilding/ transport (Prospect, 2019a). Their research has shown that EU nationals working in STEM comprise a substantial percentage of the workforce; hence withdrawing this source of labor will jeopardize capacity, operational delivery, and the reputation of UK industry (Prospect, 2019b). Leaving the EU will have wide-ranging negative impacts on the UKs nuclear industry specifically in the form of research, access to fissile materials, and the status of 20 nuclear co-operation agreements with other nations. This will also impact the country economically as it may lead to cutback in staff at nuclear facilities that supply energy, which could thus result in higher energy rates (Prospect, 2019b). Last, the credibility of UK STEM will be undermined across the board by restrictions of international collaborations as a result of Brexit, as many of these programs are supported through EU collaborations, and which may not be able to be scalable on a national level (Prospect, 2019b).

\section{SYNTHESIS}

Educating economically successful engaged global citizens; expanding access to higher education; and impacting science diplomacy, international relations, and the evolution of the academy into engines of social and economic development are issues that are addressed through the promotion and expansion of international STEM collaborations. The content analysis elucidates perspectives that show that engagements bring gifted scientists and students together from across the globe to work on issues of international significance. Hence, the essence of cosmopolitanism, global citizenship education, and the global university engagement movement are portrayed (Warden \& MacGregor, 2014).

Engagement activities through STEM often integrate community outreach into teaching, learning, and research (Warden \& MacGregor, 2014) taking advantage of the social roles of universities and their mandates of community service. For academics who pursue community-based teaching, research, and public service this offers opportunities for outreach that is seen as one of the best ways that institutions can bring engagement into the mainstream university. This is an important aspect as STEM professional must engage with those that they treat in order to address their concerns in a fashion that is sensitive to their cultural identity and needs. This illustrates the core values of global citizenship, and demonstrates that STEM education programs are natural breeding grounds for global citizenship education/competencies.

The insights garnered from the research demonstrated that the growth in international STEM initiatives has led to the rise an in global networks of community-engaged universities that actively foster university collaborations with the local and international community, and transfer knowledge in both directions. Through these collaborations, both in national and local communities are the recipients of shared learning and thus become an integral part of the formal STEM curriculum. Operating within the broad internationalized dynamic of STEM disciplines have positioned HEls to sharpen the community work of its members to support engagement that is advantageous to students and their communities.

The research also showed that engagement in international educational opportunities, including experiences in STEM, allow students to better understand their international colleagues and peers, along with sociocultural dynamics of various nations. The global citizenship competencies that are developed through these experiences will provide them with the necessary background to promote a more peaceful society. Through the bond of scientific knowledge, principles, and values participants in STEM education are drawn together through the sharing of ideas and experiences from diverse backgrounds to work on issues of global concern (Simeon, 2016; Thorson, 2012). This the formation of new relationships and understandings that will have lasting value by bringing people together and promoting new ideas.

By linking global citizenship education with that of STEM education in comprehensive holistic manners, the preparation of students will promote the understanding of informed global perspectives uninhibited by border that include various populaces and viewpoints. The ideas and policies of promoting informed global perspectives through civic engagement and citizenship are articulated by President Barak Obama in several major speeches, including his farewell address, in which he states that "scientists help...people and address critical global challenges through science and reason" (Obama, 2017). These pronouncements are an embracing of sociocultural and globally inclusive paradigms that yield beneficial results.

Returning to the illustrations regarding migration and the Southern border of the U.S. (and similar challenges 
in various European nations), some consideration may be given to the surprisingly laconic quotes of former Secretary of Defense and retired four-star General, James Mattis. Mattis said, "I hope we can find our way to engaging with one another, arguing strongly with one another, and then going down and having a root beer together or something, as we work together for the best interest of the next generation" (Mattis, 2019). By working collectively with various current and future higher education, government, and STEM professionals, hopefully, physical and cultural barriers will be dismantled.

\section{REFERENCE LIST}

American Association for the Advancement of Science [AAAS] (2014). About AAAS. Retrieved on December 21, 2019 from http://www.aaas.org/about-aaas.

American Association for the Advancement of Science [AAAS] (2019). Science Diplomacy Education Network. Retrieved on December 4, 2019 from https://www.aaas.org/programs/center-sciencediplomacy/education-network.

American Institute of Physics (24 March 2015, Number: 42). President Obama on STEM Education. Retrieved on Jan 3, 2020 from https://www.aip.org/fyi/2015/president-obama-stem-education.

Anon, J. (2019). Plenary Address to Inside Higher Education Conference. Washington, D.C. January 8 , 2019.

BBC News (2018), "Europe and nationalism: A country-by-country guide," BBC News- Europe (10 September, 2018). Retrieved on April 6, 2020 from https://www.bbc.com/news/world-europe$\underline{36130006}$

BBC News (2019), "Brexit: Ministers speak out against no-deal exit," BBC News- Europe (4 January, 2019). Retrieved on January 8, 2020 from https://www.bbc.com/news/uk-politics-46795406

Bearak, M., "Theresa May criticized the term 'citizen of the world.' But half the world identifies that way.," The Washington Post (5 October, 2016). Retrieved on December 6, 2019 from https://www.washingtonpost.com/news/worldviews/wp/2016/10/05/theresa-may-criticized-the-termcitizen-of-the-world-but-half-the-world-identifies-that-way/?utm term=.4cb9abc0f554

Blumenthal, P. (2019). Inside Higher Education Conference. January 8, 2019, Washington, DC.

Bolton, A., "Schumer: Trump has given a 'brutal and repressive dictatorship' legitimacy," The Hill (12 June, 2018). Retrieved on December 6, 2019 from https://thehill.com/homenews/senate/391821-schumerslams-north-korea-summit-weve-legitimized-a-brutal-dictator

Choudaha, R and Contreras, E. "HE internationalization- What gets measured, gets funded," University World News, Issues No: 327 (04 July 2014). Retrieved on December 6, 2019 http://www.universityworldnews.com/article.php?story=20140702133825465\&query=globalization

CIPD (2019). Brexit impact on workforce trends. Retrieved on December 7, 2019 from https://www.cipd.co.uk/news-views/brexit-hub/workforce-trends.

Clifton, K. (2019), "Boris Johnson tells anti-Brexit campaigner 'we should have no terrors' about leaving EU with no-deal," The Evening Standard (7 January, 2019). Retrieved on December 8, 2019 from https://uk.news.yahoo.com/boris-johnson-tells-anti-brexit-221053139.html

CNN (2018), "The UK government says its Brexit deal will hurt the economy?," CNN Business (28 November, 2018). Retrieved on December 8, 2019 from https://www.cnn.com/2018/11/28/economy/brexit-economic-impact/index.html

CRDF Global (2014). About Science Diplomacy. Retrieved on December 16, 2019 from www.crdfglobal.org/program-areas/science-engagement/science-diplomacy/about-science-diplomacy.

Delacruz, E. M. (2009). Visual Arts: Technology Pedagogy as cultural Citizenship. In Cope, B., \& In Kalantzis, M. Ubiquitous learning. Urbana: University of Illinois Press.

Giroux, H (2004). Neoliberalism and the Vocationalization of Higher Education. Retrieved on December 8 , 2019 from http://firgoa.usc.es/drupal/node/22831.

The Global Educator (11 February 2013). Are international schools creating global citizens? Retrieved on 
March 9, 2020 from http://the-global-educator.com/2013/11/02/are-international-schools-producingglobal-citizens/.

Hatmaker, T. (2018). "Trump's visa restrictions aimed at Chinese STEM students to start in June," TechCrunch (June 2018). Retrieved from https://techcrunch.com/2018/05/30/chinese-visas-statedepartment-trump-june-11/

Haythornthwaite, C. (2009). Participatory Transformations. In Cope, B., \& In Kalantzis, M. Ubiquitous learning. Urbana: University of Illinois Press.

Hayden, M., Rancic, B. \& Thompson, J. (2000) Being international: student and teacher perceptions from international schools. Oxford Review of Education 26 (1) 107-123.

Institute of International Education (2019). Dragon Global Citizenship Programme. Retrieved on January 7 , 2020 from https://www.iie.org/en/Programs/Dragon-Global-Citizenship-Programme

Knight, J (2008). The internationalization of higher education: Are we on the right track? in Academic Matters. The Journal of Higher Education, October/November 2008

Lindsay, B. \& Simeon, E. J. (2015). Social \& Public Engagement: Creative Nexuses for STEM Research \& International Relations. In J. Zajda (Ed.), Globalization \& Higher Education Reforms. Dordrecht: Springer.

Lindsay, B. \& Simeon, E. J. (January 01, 2014). Relationships between Global Citizenship and University Rankings. Research in Comparative and International Education, 9, 2, 243.

Mabbett, A (2018), "STEM in post Brexit Britain," Education Business. Retrieved on January 8, 2020 from http://www.educationbusinessuk.net/features/stem-post-brexit-britain

Marshall, H. (2007) Global education in perspective: fostering a global dimension in an English secondary school. Cambridge Journal of Education, 37 (3) 355-374.

Mattis, J. (2010). Face the Nation. Retrieved on January 6, 2020 from www.whitehouse.gov/farewell.

McCarthy, J., "The Hidden Message for Global Citizens in Donald Trump's Inauguration Speech," Global Citizen (20 January, 2017). Retrieved on January 6, 2020 from https://www.globalcitizen.org/en/content/president-donald-trump-speech-unga-2018/

McCarthy, J., "5 Key Issues Trump Spoke About in His UN Speech," Global Citizen (25 September, 2018). Retrieved on January 6, 2020 from https://www.globalcitizen.org/en/content/president-donald-trumpspeech-unga-2018/

Merrick, A. (2018). "It's Getting Harder for International STEM Students to Find Work After Graduation," The Atlantic (22 September, 2018). Retrieved from on December 18, 2019 https://www.theatlantic.com/business/archive/2018/09/stem-majors-jobs/568624/

National Science Foundation (2020). About the NSF. Retrieved on August 9, 2020 from https://www.nsf.gov/about/ on August 9, 2020.

Nowrasteh, A. (2018). "Commentary: How Trump is really changing immigration: Making it harder for people to come here legally," Chicago Tribune (13 May, 2018). Retrieved on March 12, 2020 from https://www.chicagotribune.com/news/opinion/commentary/ct-perspec-trump-legal-immigration-051320180513-story.html

Nye, J. (2007, November 29). Smart Power. Washington Post. Retrieved from www.huffingtonpost.com/joseph-nye/smart-power b 74725.html.

Nussbaum, M. (1996). Patriotism and cosmopolitanism. In Nussbaum, M. C., \& Cohen, J. (Eds.). For love of country: Debating the limits of patriotism (pp. 2- 20). Boston: Beacon Press.

Obama, B. H. (2017). Presidential Farewell address. Chicago, Illinois. January 10, 2017. Retrieved on January 6, 2020 from www.whitehouse.gov/farewell.

Partington, R. (2018), "UK businesses told to expect workforce crisis after Brexit," The Guardian (28 March, 2018). Retrieved on January 8, $2020 \mathrm{from} \mathrm{https://www.theguardian.com/global/2018/mar/29/uk-}$ businesses-workforce-crisis-brexit-young-workers.

Pierce, S. \& Selee, A. (2017). Immigration under Trump: A Review of Policy Shifts in the Year Since the Election. Retrieved on January 6, 2019 from https://www.migrationpolicy.org/research/immigrationunder-trump-review-policy-shifts 
IJAEDU- International E-Journal of Advances in Education, Vol. VI, Issue 17, August, 2020

Pierce, S., Bolter J., \& Selee, A. (2018). U.S. Immigration Policy under Trump: Deep Changes and Lasting Impacts. Retrieved on March 16, 2020 from https://www.migrationpolicy.org/research/us-immigrationpolicy-trump-deep-changes-impacts

Prospect (2019a). About Us. Retrieved on January 7, 2020 from https://www.prospect.org.uk/about/index

Prospect (2019b). Brexit and STEM: Experience from the frontline. Retrieved on January 7, 2020 from https://www.prospect.org.uk/be-involved/brexit/brexit-stem/.

Rhodes, R. A. and Szelenyi, K. (2011). Global citizenship and the university: Advancing social life and relations in an interdependent world. Stanford, California: Stanford University Press.

Rizvi, F. (2009). Towards cosmopolitan learning. Discourse. 30: p. 253-268.

Royal Society (2010). New frontiers in science diplomacy: Navigating the changing balance of power. London: The Royal Society.

Semotiuk, A. (2018). "Foreign Students to Deal with Uncertainties Under New U.S. Immigration Policy," Forbes (13 June, 2018). Retrieved on February 12, 2020 from

https://www.forbes.com/sites/andyisemotiuk/2018/06/13/raising-the-bar-on-international-students-newuscis-policy-looks-to-target-college-students/\#7bf6f19055fb

Simeon, E. J. (2016). Factors that Influence Underrepresented Racial \& Ethnic Minority Students' Success in Graduate STEM Programs in the United States \& England (Doctoral dissertation). Education Resource Information Center (ERIC), Number: ED595992. Retrieved on January 15, 2020 from https://eric.ed.gov/?id=ED595992.

Simeon, E. J. \& Lindsay, B. (2015, July). Science, Technology, Engineering, \& Math (STEM) Collaborations: Opening New Frontiers for Cosmopolitan Global Citizenship Education \& International Affairs. National Science Foundation Grants \#1306506 \& 1238396, Equality, Diversity, Inclusion Conference, Tel-Aviv, Israel.

Smith, D. G. (ed) (2014). Diversity and inclusion in higher education: Emerging perspectives on institutional transformation. London and New York: Routledge

Starkey, H. W. (2017). Globalization and Education for Cosmopolitan Citizenship. In J. A. Banks (Ed.), Citizenship Education and Global Migration: Implications for Theory, Research, and Teaching. Washington, DC: American Educational Research Association.

Tau, B., "Obama asks geography bee question," Politico, Blog (24 May, 2012). Retrieved on January 6, 2019 from https://www.politico.com/blogs/politico44/2012/05/obama-asks-geography-bee-question-124490

Tharoor, I., "Brexit marks the revenge of a nation," The Washington Post (28 June, 2016). Retrieved on March 6, 2020 from https://www.washingtonpost.com/news/worldviews/wp/2016/06/28/brexit-marksthe-revenge-of-a-nation/?utm term $=.00944 \mathrm{f} 1995 \mathrm{b9}$

The Balance (2019). Bretton Woods System and 1944 Agreement: How Bretton Woods Introduced a New World Order. Retrieved on January 7, 2020 from https://www.thebalance.com/bretton-woods-systemand-1944-agreement-3306133

The Week Business (2019), "Fact check: what is a no-deal Brexit?," The Week Business (4 January, 2019). Retrieved on January 8, 2020 from https://www.theweek.co.uk/fact-check/95547/fact-check-what-a-nodeal-brexit-really-means

Thorson, S. J., "Universities and Networks: Scientific Engagement with North Korea," Science \& Diplomacy, Vol. 1, No. 2 (June 2012) www.sciencediplomacy.org/article/2012/universities-and-networks.

Trotta-Tuomi, M., Jacott, L., \& Lundgren, U. (2008). Education for World Citizenship: Preparing students to be agents of social change. European Commission. London Metropolitan University.

Turak, N. (2018). "American higher education at risk from immigration policies, says USC president," CNBC (21 February, 2018). Retrieved on December 22, 2019 from https://www.cnbc.com/2018/02/21/ushigher-education-at-risk-from-trump-immigration-policies-usc.html.

U.S. Embassy London (2014). The work of the U.S. Embassy in London's ESTH Unit [Interview transcript]. Conducted on May 30, 2014. London, England.

University of California Davis (2019). UCDAR Consortium. Retrieved on December 7, 2019 from http://sjoseph.ucdavis.edu/ucdar/. 
Watson, D. (2011). The engaged university: International perspectives on civic engagement. New York: Routledge.

Warden, R. \& MacGregor, K. Forging the future of university engagement- Talloires 19 December 2014 Issue No: 348. Retrieved on January 6, 2020 from http://www.universityworldnews.com/article.php?story=20141219105358283.

Washington Post, "Obama Holds a Town Hall in Istanbul," Washington Post, Transcripts Wire (7 April, 2009). Retrieved on January 6, 2020 from http://www.washingtonpost.com/wpdyn/content/article/2009/04/07/AR2009040701463.html. 